\title{
A Mixed-Methods Approach to Understanding Funder Trust and Due Diligence Processes in Online Crowdfunding Investment
}

\author{
HELEN S. JONES, School of Psychology, University of Central Lancashire \\ WENDY MONCUR, School of Nursing and Health Sciences, University of Dundee; \\ Duncan of Jordanstone College of Art \& Design, University of Dundee
}

\begin{abstract}
We report on two studies undertaken to establish the factors that affect funders' trust and likelihood to invest in crowdfunding campaigns online. Findings from an initial small-scale qualitative study are reported and subsequently triangulated in a larger quantitative survey. Across these studies, we demonstrate the importance of social information within the peer economy, with a strong reliance on other users across the course of the investment decision-making process. Decision making on whether to invest is informed not only by the content of the crowdfunding campaign page but also by social influence factors that are present (e.g., liking of the campaigner, reciprocity). It is further shaped by due diligence checks focused on the progression of the prototype for which funding is sought, and by assurances from outside the campaign page-namely on social media. Such assurances center around the importance of social proof, garnered through opinions of previous customers or other funders. The risk here is that much of this information is content that can be faked, and as such a reliance on this may leave potential funders vulnerable. Meanwhile, a genuine lack of prior experience and customer base means that some legitimate campaigners struggle to gain trust from potential investors who are reliant on such social information. Our findings present an empirical grounding to develop future security solutions that (1) protect existing funders and (2) increase potential funders' level of trust, to encourage their engagement with legitimate crowdfunding campaigns.
\end{abstract}

CCS Concepts: • Security and privacy $\rightarrow$ Human and societal aspects of security and privacy; Social aspects of security and privacy; $\bullet$ Applied computing $\rightarrow$ Law, social and behavioral sciences; Psychology;

Additional Key Words and Phrases: Crowdfunding, trust, social media, investment, decision making, social influence, finTech

\section{ACM Reference format:}

Helen S. Jones and Wendy Moncur. 2020. A Mixed-Methods Approach to Understanding Funder Trust and Due Diligence Processes in Online Crowdfunding Investment. ACM Trans. Soc. Comput. 3, 1, Article 3 (February 2020), 29 pages.

https://doi.org/10.1145/3373148

This research was supported by the Engineering and Physical Sciences Research Council [Grant reference: EP/N02799X/1]. Authors' addresses: H. S. Jones (corresponding author), School of Psychology, University of Central Lancashire, Preston, PR1 2HE, UK; email: hsjones1@uclan.ac.uk; W. Moncur, Duncan of Jordanstone College of Art \& Design, University of Dundee, Dundee, DD1 4HT, UK; email: w.moncur@dundee.ac.uk. \footnotetext{
0 License.

(c) 2020 Copyright held by the owner/author(s).

2469-7818/2020/02-ART3

https://doi.org/10.1145/3373148
}

This work is licensed under a Creative Commons Attribution-NonCommercial-NoDerivs International 4. 


\section{INTRODUCTION}

In this article, we focus on crowdfunding as a commercial manifestation of truth and trust enacted through peer-to-peer investment. We explore what information sources funders use to establish trust when deciding which campaigns to invest in, and consider risks emanating from the potential unreliability of that information.

\subsection{Crowdfunding}

Crowdfunding has emerged in recent years as an alternative method for new businesses to raise capital, either to progress their business or to take a specific new product to market. These small businesses typically lack the financial history or stability to allow for corporate investment [1] and so instead build an online campaign to garner multiple small investments from peers. The emergence of crowdfunding can be understood within the societal shift toward a postdigital age, where online-offline boundaries are increasingly blurred, and investor trust in large institutions and organizations (e.g., banks, hotels) has reoriented somewhat to a more peer-based approach, leveraging financial technologies (finTech).

There are two prominent models of crowdfunding: reward based and equity based. Reward-based crowdfunding involves peer pledges being rewarded by a token gesture from the business, which can be as small as a "thank you" message or as large as a preorder of the product being launched. Equity-based crowdfunding, on the other hand, gives the funder a small stake in the business, which results in ongoing financial remuneration as the business grows and expands.

\subsection{Trust, Risk, and Uncertainty}

One crucial element of the crowdfunding process is for a funder to develop a level of trust in the campaigner. As with any commercial or business activity, the development of trust between a consumer (or funder in this case) and business owner (the campaign creator) is pivotal to investment, and as such to business success [2]. One core difference between traditional e-commerce and crowdfunding, though, is the unique type of uncertainty experienced in the latter, as the product is often at the prototype stage when funding is sought [3]. This means that additional judgments are required on the part of the funder to assess the capability of the campaigner and achieve the assurance needed to establish trust. Trust is defined in many ways across disciplines, but the persistent theme is the presence of risk and uncertainty in a decision. A definition that encapsulates these key concepts comes from Rousseau et al. [4]: "trust is a psychological state comprising the intention to accept vulnerability based upon positive expectations of the intentions of behaviors of another." A crowdfunder's investment reflects trust that the campaigner has good intentions to deliver the promised product, and that the campaign is legitimate.

Risk and uncertainty for the funder lie in whether a product/business being advertised will be delivered as expected. Unlike other online marketplaces, there are additional layers of uncertainty in crowdfunding, based on the lack of accountability and regulation of campaigns that either do not deliver a product or do not deliver it as advertised [5]. Potential funders must therefore simultaneously bring greater scrutiny and greater trust when considering whether to invest. These tensions can undermine investment likelihood if funder trust is not established successfully [6]. Indeed, despite the continued growth of crowdfunding platforms as an alternative funding source, the average success rate of campaigns is less than $50 \%$, with over half of campaigns never reaching their funding goal. A lack of trust that the campaigner will be able to deliver the advertised prod$\mathrm{uct} /$ business plan is often reported as a common disincentive for funders [7]. Previous research has often acknowledged trust as a predictive factor to investment/purchase behavior in e-commerce and crowdfunding (e.g. [8, 9]). However, as noted by researchers in this field (e.g., Liang et al.), 
little research has explored the specific factors that contribute to the manifestation of trust. The research presented in this article builds on the existing literature in an attempt to create a clearer picture of the factors affecting trust and investment likelihood, with specific emphasis on the social psychological mechanisms that can influence decision making.

\subsection{Due Diligence and Fraud}

Where funders do engage, the scale of investments typically associated with crowdfunding is smaller than traditional investment models, meaning less perceived risk. In line with the Elaboration Likelihood Model (ELM [10]), which outlines two distinct information processing routes within the decision-making process-central (critical evaluation of information associated with the decision being made) and peripheral (reliance on overall impression of information without careful examination) - the low motivation associated with a smaller investment may lead to overreliance on peripheral processing to inform decisions. As such, funders may be less likely to engage in time-consuming "due diligence" assessment of a campaigner [7]. Due diligence refers to actions taken to ensure that an activity is safe. With regard to crowdfunding, due diligence checks allow potential funders to build confidence in their investment and trust in the campaigner. This may typically involve background checks to ensure the legitimacy and viability of the campaigner as an unknown party.

A lack of such due diligence can leave the funder more vulnerable to fraudulent campaigns, where risks include not only loss of investment but also loss/misuse of personal information linked to the funding (as seen in the case of Erik Chevalier [11]), and even risks to personal safety (e.g., where funders were allegedly threatened by the fraudulent campaigner Douglas Monahan [12]). The harm done by fraudulent campaigns extends beyond harm to individuals: there is also potential harm to funders' overall trust in crowdfunding as an investment vehicle. Reduced trust may deter potential funders from investing with legitimate crowdfunding campaigns as a result [13]. As such, it is important to tackle the issue of fraudulent campaigns before funders become victims, and a thorough understanding of the due diligence process can work toward achieving this. By understanding the processes that determine current due diligence practices, as we attempt to do in the research presented in this article, it will be possible to encourage optimal practice in funders to ensure their protection against fraudulent campaigns.

\section{LITERATURE REVIEW}

Previous literature that explores crowdfunding success has focused predominantly on patterns of investment and the motivations that lead funders to pledge support for a campaign, in an attempt to increase the profitability for creators [15]. This literature provides valuable insights from an economic perspective, but there is little emphasis on understanding how trust manifests in relation to crowdfunding, and the psychological mechanisms underlying funder decision making. However, Liang et al. [2] have recently outlined a theoretical model that draws upon Kim et al.'s [15] e-commerce decision-making model to explain trust-based decision making specific to crowdfunding. This model highlights four core factors that influence investment decisions: project information quality, fundraiser ability, fundraiser reputation, and value similarity. In this review, these four factors are outlined, alongside relevant literature, before being related to complementary social psychological mechanisms to further explain the decision-making process.

Project information quality focuses on the content available through the campaign page itself-something that has been further reiterated in research that analyzes campaign pages to establish predictors of success (e.g., campaign word count and use of a campaign video [14]). Liang et al. found fundraiser ability to have the largest effect size, though, in relation to predicting trust, which is in line with other research demonstrating the importance of prior campaign success 
and reciprocal funding (e.g., [16, 17]). This is further supported by analysis of proven fraudulent campaigns on crowdfunding platforms, through which Cumming et al. [18] demonstrated that previous crowdfunding experience is a valid indicator of legitimacy, with fraudulent campaigners being less likely to have orchestrated previous campaigns. Campaign history alone, though, cannot be relied upon as an indicator of trustworthiness, given that a lot of crowdfunding campaigns are run by startups that are launching their first product.

As such, this demonstration of ability is often also perceived through social information available to a potential funder, which ties in with the notion of fundraiser reputation. The lack of experience for many start-up companies launching crowdfunding campaigns means that reputation in the business sense can be a difficult asset to demonstrate to potential funders. Metrics such as "likes" on the campaign page or reviews from previous customers can increase investment likelihood though, where these are available [14]. In line with this, there is evidence to suggest that the most common type of updates on a campaign page are those that attempt to garner social promotion, through requests to share the campaign with friends and across social media [19].

Social media itself can act as a valuable source of social information about a campaigner, although it is not explicitly outlined within Liang et al.'s model. Research demonstrates a link between social media presence and increased likelihood of receiving funding [20,21], although this is typically data gathered through secondary analysis of campaign pages. Social media can provide both due diligence around the legitimacy of a campaigner and additional social information and networking opportunities that can increase the feeling of connectedness. However, an overreliance on information gathered from social media brings inherent risk due to the increasing ease with which social media information can be manipulated [22]. Information that may be taken to indicate a well-connected and reputable campaigner or organization-such as number of followers and number of likes on posts-can be artificially generated with ease to create an illusion of social support and engagement. Based on the prominence of diverse social information acting as a metric for establishing trust in a campaigner, we propose that rather than "funder reputation" as outlined by Liang et al., "funder social credibility" may be a more encompassing factor in the decision-making process. This emphasizes the role of reputation, alongside crucial demonstration of connectedness and communication from the campaigner [23] through the campaign page and social media.

Within rewards-based crowdfunding, a desire to own the product or collect the reward is often reported as a strong predictor of investment likelihood [6], which supports the notion of value similarity, in the sense of shared interests, being a final important factor in the decision-making process, as outlined by Liang et al. Across all of these factors, there are parallels with the six principles of persuasion outlined by Cialdini (reciprocation, liking, social proof, commitment, authority, and scarcity [24]). These principles are often cited in relation to decision-making processes, in particular around business and marketing. Evidence demonstrates that when a person supports the campaigns of others, others in turn are more likely to support them [17]-highlighting the principle of reciprocation. Activity on social media and the campaign page may elicit perceptions of social proof (e.g., through the active support of other users [14]), liking (e.g., through a shared interest in the product area and value similarity [2]), and commitment (e.g., through project updates [19] and engagement with funders). Evidence of these social influence principles may therefore increase the likelihood of investment, based on the great importance that humans put on social information to inform behavior (as seen in social learning theory [25]). Therefore, this research will consider the factors that inform trust decisions in crowdfunding, with particular emphasis on the role of social media and placing key factors within the framework of Cialdini's principles of persuasion. 
Much previous research has considered the frequency of campaign successes in relation to social information availability, through secondary data analysis of campaign page content (e.g., [5, 17, 21]) or through data from project campaigners (e.g., [20]). However, little research has asked funders firsthand how social information, and in particular social media, influences their decisionmaking process. In order to understand the best ways to protect users from risks such as fraudulent crowdfunding campaigns and implement secure practice, it is important to initially understand the mechanisms they currently employ to make decisions and the due diligence conducted to protect themselves. Although patterns in existing data are valuable from a business perspective to increase campaign success, behavior change and solutions designed to improve security need to be generated from the perspective of the users themselves in order to maximize effectiveness. As such, we aim to address two core research questions within this article:

RQ1: Based on firsthand insights from crowdfunders, what factors underpin the investment decision-making process and development of trust in a campaigner?

RQ2: What due diligence processes do crowdfunders currently engage in, both on the campaign page and through external social media pages?

\section{CURRENT RESEARCH}

In this article, we take a mixed-methods approach to address the research questions outlined above. The two studies presented explore the investment decision-making process, including factors within the crowdfunding campaign itself, as well as the influence of social media and the typical due diligence processes that users engage with. As outlined above, this research draws on the firsthand experiences of crowdfunding users in an attempt to replicate findings that have been highlighted in analysis of secondary data, while also building on the decision-making model outlined by Liang et al. [2], with the incorporation of information from social media as an additional metric that may inform investment decisions.

The first study presented takes a qualitative approach, providing a rich dataset from 11 users with experience in crowdfunding, to explore factors that affect funders' trust and likelihood to invest in crowdfunding campaigns online. The second study $(n=139)$ triangulates these findings through a quantitative survey, to provide mutual validation of the data and present a more complete and empirically valid account of investment decision making [26]. This study also introduces individual difference factors between users that might influence the decision-making and due diligence processes that they engage in. Across these studies, our results demonstrated the influence of the campaigner, social information, and the product in the investment decision-making process. Decisions on whether to invest were informed not only by the content of the crowdfunding campaign page but also by social influence factors that were present (e.g., liking of the campaigner, reciprocity). They were further shaped by due diligence checks focused on the progression of the product prototype for which funding was sought, and through assurances garnered through opinions of previous customers or other funders on social media, outside of the campaign page. In reflecting on our results, we consider the risks inherent in this approach to due diligence. Much of the information used as input is content that can be faked or produce unreliable signals to legitimacy. Reliance on it may leave potential funders vulnerable to fraud. Meanwhile, some legitimate campaigners may struggle to gain trust from potential investors who are reliant on such social information, due to a genuine lack of prior experience and customer base.

The research reported herein was undertaken as part of a wider endeavor-TAPESTRY [27]which is developing a novel blockchain-based security service for reliably proving the provenance of online digital identity. Our findings on factors that affect funders' trust and likelihood to invest in crowdfunding campaigns serve as input to the design of this service, by highlighting the metrics 
that users typically rely on. Verification of these metrics will act as an assistive tool to help nonexpert users (such as crowdfunding investors) make better decisions about whom to trust online. By drawing attention to potentially unreliable signals and false online identities, we anticipate that this security solution will protect funders from investing in fraudulent campaigns while simultaneously increasing their level of trust and engagement with legitimate crowdfunding campaigns.

\section{STUDY 1: EXPLORING FACTORS THAT INFLUENCE CROWDFUNDING INVESTMENT DECISIONS-A QUALITATIVE STUDY}

This study takes a qualitative approach to explore the factors that funders recognize as important to establishing trust when deciding which campaigns to invest in. Building on previous research that has explored motivations to fund and success signals in a campaign page, this research focuses on the decision-making process. This includes the social influence factors that increase investment likelihood, as well as the due diligence processes that funders typically go through on the campaign page and through external sources such as social media. This is an initial exploratory study, using interview and focus group methods, designed to highlight key themes in relation to these core processes within crowdfunding. Based on the participants sampled, there is a predominant focus on users of reward-based rather than equity-based crowdfunding in this dataset.

\subsection{Materials and Methods}

Ethical approval for this research was granted by the University of Dundee School of Nursing and Health Sciences Research Ethics Committee. All participants gave fully informed written consent before taking part.

4.1.1 Participants. A total of 11 participants were recruited for this study, with 9 males and 2 females. The mean age of this sample was 26.82 years $(\mathrm{SD}=8.28)$, with an age range from 19 to 48 years. This sample was recruited through online adverts, and all participants had prior experience of funding people that they did not know personally through crowdfunding platforms. The recruitment criteria around crowdfunding experience and limited availability of participants meant that there was an element of self-selection bias in the sample gathered as there were not enough potential participants to allow for random sampling. However, recruitment efforts were expanded to reach national and international participants, allowing a sequential sampling method with opportunity to recruit participants from a more diverse participant sample, until a point of data saturation. Only once data saturation had been reached were recruitment efforts stopped, ensuring an adequate sample size appropriate for the research being conducted [28].

\subsubsection{Materials.}

Participant questionnaire. Prior to the interview, participants were asked to complete a brief demographic questionnaire, which included eligibility questions about their prior experience with crowdfunding platforms. Following this, participants were asked to indicate their availability to participate in the interview part of the study. Participants who indicated that they had previously funded individuals they did not know personally were then invited to participate in the interview stage, based on the availability that they had indicated.

Interview protocol. Participants were invited to take part in a discussion about their experiences on crowdfunding platforms. This discussion took the form of either focus groups or one-on-one interviews. Variation was due to practicalities in interviewing participants, some of whom were located nationally and internationally, and as such sessions were arranged to suit their availability. A very similar protocol was used in each of these formats, providing a set of core questions that were then adapted to explore points of interest further during the data collection session. The 
protocol was developed based on the research questions outlined above. Topics covered using this protocol included background information about involvement in crowdfunding, investment decisions, negative experiences, perceptions of security risks associated with crowdfunding, due diligence processes, and potential added assurances that might alleviate security concerns.

Procedure. Initially, participants were recruited in the local area to take part in focus group sessions. The research was advertised on Facebook, Twitter, and Reddit, via the researcher's personal accounts, with the posts then being shared by local community groups. Poster adverts were also placed across the university, with participants asked to sign up via an online form that also allowed them to indicate their availability to take part. For the first focus group, six participants attended a session within the University of Dundee. Upon arrival, participants were given a written and verbal overview of the research and invited to ask any questions.

Limited availability of multiple participants at the same time in the local area resulted in an initial move to online focus groups, which allowed for wider advertisements, and the researcher's social media posts were targeted at crowdfunding groups globally. The practicality of running sessions with multiple participants simultaneously again proved difficult though, with limited participant sign-ups and availability. This led to a decision instead to conduct one-on-one interviews at a time that suited the participant. One online focus group was conducted with two participants, and then a further three one-on-one interviews were conducted (two online via Skype and one offline). Using Skype to conduct the interviews meant that the research was also able to reach a wider audience, thus reducing bias based on the geographical location of the participants.

For all participants, the initial online sign-up stage allowed for completion of the participant questionnaire, as well as indication of availability. All focus groups and interviews were carried out by the lead researcher, based on the interview protocol outlined above. Questions were adapted to fit the discussion of the particular group or interviewee to allow for flexibility and ensure maximum insight was gained. All discussions were audio-recorded and later transcribed for analysis. Thematic analysis was conducted following standard guidelines from Braun and Clarke [29], which cover six phases of data analysis. Transcripts were first read for familiarization and then broken down into initial codes based on commonalities seen across the dataset. At this point, individual quotes/points were drawn out that related to these initial codes. The codes were then grouped together to generate themes and subthemes, with quotes relevant to core concepts collated together. Following initial coding and a review of the themes, interrater reliability was calculated with a second coder analyzing $10 \%$ of the data. This produced an interrater agreement of $75 \%$, following which discussions were held to allow for clarification of judgments and finalizing of themes within the codebook. As a result, both raters were confident that the final codebook was representative of the key themes within the data and was suitable for production of the results reported in the following section.

\subsection{Results}

4.2.1 Crowdfunding Experience. Within our participant sample, $64 \%$ of participants reported that they had previously used crowdfunding for both funding projects and raising money for their own projects. The remaining $36 \%$ had used crowdfunding only for funding others. With regard to type of crowdfunding, $73 \%$ of our sample had been involved only with rewards-based crowdfunding, while $27 \%$ had been involved in both rewards- and equity-based crowdfunding.

4.2.2 Construction of Themes. In line with the semistructured nature of the interview protocol designed for this research, a similar pattern of topics emerged during thematic analysis of the data. Across the focus groups and interviews conducted, 4 key themes, with 10 subthemes, emerged. 
Table 1. Framework of Crowdfunder Interview Themes

\begin{tabular}{ll}
\hline Theme & \multicolumn{1}{c}{ Subtheme } \\
\hline 1. Initial interest in the campaign & 1.1 Desire for the product \\
& 1.2 Online promotion \\
& 1.3 Personal interest \\
2. Decision-making process & 2.1 Content on the campaign page \\
& 2.2 Social influence \\
3. Due diligence & 3.1 Progression of prototype \\
& 3.2 Assurances \\
& 3.3 Risk factors \\
4. Maintaining trust posti nvestment & 4.1 Communication from the campaigner \\
& 4.2 Desired assurances \\
\hline
\end{tabular}

These are outlined in Table 1 and discussed in more detail below. Results will be outlined under each of the four themes, with subthemes discussed within these.

4.2.3 Initial Interest in the Campaign. When it comes to finding crowdfunding campaigns to invest in, the majority of participants indicated that they most often heard about these from thirdparty websites, rather than by browsing crowdfunding platforms. Many participants reported seeing campaign coverage on social media or other community pages, "either via blogs, Facebook where somebody else has liked something" (Participant 11). Facebook and Twitter were the prominent social media sources mentioned, typically reached either from the company advertising their own campaign or from a friend's activity on a social media feed.

A personal interest in the project category (e.g., gaming, technology, film) was found to be an important influence, with "something that I'm interested in or passionate about" (Participant 7) being more appealing. More specifically, a number of participants emphasized that their interest was piqued by a desire to own the product being advertised and ensure that it is produced: "I wanted it; I wanted the game, wanted the limited-edition version of the game. So they had me straightaway" (Participant 13). In some cases, participants admitted that the desire to own the product may result in them "accepting the risk that it might not deliver and just putting my money there" (Participant 4).

4.2.4 Decision-Making Process. Having demonstrated an initial interest in a crowdfunding campaign, the potential funder then typically spends time analyzing the campaign page and making a decision on whether to make a pledge. This decision-making process is influenced by the content on the campaign page itself, and by social influence factors.

Campaign page content. The campaign page itself is screened: participants looked for numerous cues to the likelihood of success, as well as the legitimacy of a project. An overall impression of professionalism and competence from the campaigner was mentioned by many participants, as an indicator that "this creator has done their homework" (Participant 12). Evidence that effort and money has been put into setting up a campaign also adds a level of assurance, demonstrating dedication to the project, with one participant outlining the key campaign page attributes that he or she is looking for: 
"I then look at whether the quality of Kickstarter campaign looks like it's had some money poured into it, so does it look legitimate, is it like a chunky jumbo campaign where they have stages, you know, a product plan they've followed and do they have like defined deadlines and do they already have the manufacturing tied down." (Participant 11)

This idea of a clear plan for the project was deemed important, as was recognition of "risk details, so people could see whether [they] were likely to fail or what not and you knew what you were getting into" (Participant 11). The recognition of potential risk factors demonstrates a higher degree of knowledge around the crowdfunding process, providing added reassurance for a potential funder. One element that was persistently recognized by participants as demonstrating effort and commitment to the project was the presentation of a campaign video. In some cases, the mere presence of a video provided assurance, as this means "it wasn't so easy to just mock up a campaign" (Participant 11), given that this requires a lot more time than simply setting up a page. Others emphasized the importance of video quality, with consideration of "how professional the video has been made, you know sometimes they post a video that are not really good, you know, they just, it seems like they made it with an iPhone or like with a very cheap tool" (Participant 1). While videos go some way to providing the potential funder with reassurance, it is clear that there are gradients in the impact this can have on investment likelihood dependent on quality. Videos were deemed more useful if they contained footage of the product, or prototype, rather than "just people talking about what they want to do, instead of showing what they've already done" (Participant 2). The video was not deemed as much of an assurance for one participant though, who commented that "they can plough loads of money into making a great video but then still...not produce a product at the end of the day" (Participant 6).

Social influence. Aside from the content of the campaign page itself, participants highlighted decision-making factors that relate to social influence techniques outlined in the Literature Review section of this article. Many participants indicated that they would be more inclined to support a campaign being run by a company that they had previously interacted and were familiar with, either through prior crowdfunding campaigns or through purchases outside of these platformsfor example, when a potential funder has "partially played three previous games in the series so I just thought, hey this looks good, why not put some money into it" (Participant 2) or "somebody that you'd already be interested in is bringing something to market or trying to and they can only use crowdfunding as a method to bring it" (Participant 11). This type of past interaction can instigate "an innate trust too anyway, because I kind of had knowledge of them" (Participant 13). In cases where the company is not familiar, participants reported that they were often reliant on the behavior of others to guide their investment decisions, choosing to fund campaigns that "people with similar interests seem to have a good opinion of' (Participant 5). This also included an inclination to simply follow the crowd, when "they [the campaigner] got a lot of coverage which, again, then made more people sign up to back it. I probably did get swept up a little bit in that" (Participant 13). This was also amplified in some cases by a desire to help out the campaigner, getting into the "ethos" of what crowdfunding is about, "contributing to a project just to see it succeed" (Participant 12).

The campaigners themselves can have an important role in the decision-making process, with participants reporting that they are more likely to support someone with "sincerity," encouraging the potential funder to "believe in them, rather than the product" (Participant 11). A more personable approach was appreciated, as it was thought that this means "people can engage, especially if maybe [their] target audience can relate to them [the campaigner]" (Participant 3). Participants also reported anecdotes indicating that campaigners who they liked, or "were very funny" (Participant 13), were more likely to elicit funding, as opposed to campaigners who were overly self-assured about 
the worth of their campaign, and as such were not personable. On the other hand, Similarly, a "sense of entitlement" was deemed an off-putting factor that may deter potential funders:

"I can't even word it, but like it's more of a 'this needs to happen,' almost like 'I deserve this to happen to me, 'kind of thing. And I much prefer that tone of 'there's no other way of this happening, please help, and if you don't that's ok,' but you know, there's this idea and they're trying to make it happen. Like it really puts me off when people are like, I've even seen people share on Facebook if it's half way through and not enough people have donated just kind of rant on Facebook 'why are people not helping, what have I done wrong?' Well, that's it, that's what you've done wrong, you know. So I think that weird sense of 'I deserve to be helped in this' really puts me off." (Participant 14)

Many of these influential factors may be overlooked though when a limited edition version of the product is available for purchase, eliciting a sense of scarcity and increasing investment likelihood, with supporters spending " $f a r$ too much money on it" (Participant 13). Additional influence may come from a feeling of reciprocation owed to other crowdfunding users. Participants who had previously run their own campaigns reported an increased need to "pay back" this investment to others, having "contributed more to pages since then, since having the experience of asking people for that” (Participant 14).

4.2.5 Due Diligence. In general, participants recognized that there was some level of risk associated with crowdfunding investment, although none specifically highlighted concern about fraudulent campaigns or false identity of campaigners. Instead, such cases were considered an inherent part of engaging with crowdfunding:

"The scams, as far as I understand, are generally like legal. People have agreed to back something with a known risk and the risk comes from, in most cases, people misunderstanding what they're agreeing to as part of the Kickstarter process." (Participant 11)

Participants were more focused on risks around the "likelihood the project will be completed and fears over money security" (Participant 7). When considering the legitimacy of a campaign, participants considered (1) prototype progression; (2) assurances of success likelihood, based on the campaigner's history and track record; and (3) the level of financial risk.

Prototype progression. Participants reported the importance of the prototype progression as a key factor in their investment decision. Those campaigns that have "got something they were ready to deliver and they just want the money to pay for mass printing or something" (Participant 11) are deemed more trustworthy than those that, for example, have "still got research and development to do" (Participant 11). In cases where the product is delivered, participants are concerned about it "being sort of not nearly as good quality as you wanted" (Participant 2). Therefore, it seems that rather than the legitimacy of a crowdfunder as an individual, participants may be more focused on their competency to deliver the product advertised. This is further evidenced in the type of assurances that participants look for when conducting due diligence before making investment decisions, discussed in more detail below. For some participants, the risk factors highlighted are mitigated by the use of a well-known crowdfunding platform such as Kickstarter or IndieGoGo, as "the third-party crowdfunding platform calms most of my security fears" (Participant 7).

Assurances. Although a large number of crowdfunding projects come from first-time campaigners, participants reported that one of the primary things they look at to provide assurance before 
investing is the campaigner's history and past project success. One participant outlined his or her typical thought process:

"The first thing [I would look for] would be past Kickstarters. Have they produced something? Is it in the same sort of ball park as this, and has maybe showed success? If it's showed success, looking through the timelines, so they might deliver something on time, are people happy with it? If there has been a problem with it, have communications been solid? Do they deal with issues in supply chain?' (Participant 11)

Other participants reiterated these comments, noting " what I'd care more about is ... their ... previous successes and failures" (Participant 5). As mentioned above though, there is often not scope to analyze previous successes as many campaigners are new to the platforms. As such, additional assurances can provide peace of mind in place of this. Within the campaign page itself, potential funders gain insight from questions raised by others:

"Other people who have maybe asked questions of the person beforehand and I've relied on the fact that there is, not a forum, but there's a page where their communications are listed to find out more about the product, and in some cases, assure myself that it does meet my needs or that it's a legitimate product, so in an indirect kind of way."(Participant 11)

As well as eliciting objective information about the product, the communications between other funders and the campaigner also provide valuable social information. As such, both positive and negative comments are deemed useful:

"I like to see both [excited comments and concerns] because exciting things make me more excited and concerns are an opportunity for me to see how well a project creator problem solves it or addresses it or how they handle it." (Participant 12)

This management of communication with existing investors acts as a valuable assurance to additional potential future investors. A record of rapid and personal response to queries, such as "responding individually within 24 hours" (Participant 12), emphasizes a campaigner's engagement with the project. Further to this, the way in which they respond can affect perceptions of their trustworthiness, "if they're dismissive, negative etc., [they are] not trustworthy in my eyes" (Participant 7).

Assurances can also come from the number of funders already supporting a campaign, as a result of "acting out of human nature where, because I don't know these people and they're strangers, I'm looking for others that have vetted it for me" (Participant 12). The support of others is often perceived as verification that "the project is ... hugely successful, probably like the product is going to be amazing because they put a lot of effort into marketing and the video and promotion of their idea" (Participant 1). Some participants reported more in-depth consideration of the project progress and funding to date as necessary for the development of trust, with a larger funding cohort needed to establish social proof, as demonstrated here:

"Let's say it's a 10,000 dollar project and they have 3,000 dollars funded so far and that 3,000 dollars is coming from 100 people, that's not an investment but it's a sizeable contribution from a large group of people. If that was 3,000 dollars coming from 10 people, that could just be 10 of that project creator's best buddies. At that point I still haven't established that trust. I'm looking for a larger group." (Participant 12).

Seeking these types of assurances can evolve outside of the crowdfunding platform, with participants noting that they look "to see if they [the campaigners] have their own personal forum, like how 
they directly interact with the fans on their own platform as well as on things like Facebook and Reddit and what not" (Participant 2). As this participant mentions, these types of online background checks often lead to social media pages run by a company or campaigner, and most participants confirmed that they use these to inform an investment decision. Simply having social media accounts linked to a campaign provides an initial level of assurance to participants, demonstrating that "they value what social media or Facebook bring to the table and do they prioritize the importance of being engaged with it" (Participant 12). This engagement with consumers outside of the crowdfunding platform "can also be a bit more personal as well, so you kind of have a face to the project. ... There's actual people you can hold accountable for it" (Participant 3). Participants predominantly reported using Facebook, Twitter, and Instagram as external sources of assurance when making investment decisions. While a business-related Facebook page was desirable, even having a personal account linked provided some level of assurance to the identity of the campaigner:

"I mean I'd prefer them to have a [Facebook] page dedicated to whatever the project is. If they didn't have that, I'd be a little hesitant but as long as they had maybe their own Facebook profile page connected, then I'd probably be pacified there." (Participant 12).

As with other online content, social media provides valuable data demonstrating how campaigners interact with their consumers and investors. The frequency of activity, as well as consistency, and professionalism are taken as indicators of legitimacy through social media: "if the writing is bad you are more concerned about levels of professionalism and potentially quality assurance" (Participant 7). In addition, the number of followers and the way in which an organization engages with them on social media was deemed a valuable indicator of their trustworthiness, with one participant suggesting that this can be a deciding factor in investment decisions: "if they interact with people on the social media as well, I'd be more likely to back them" (Participant 13). Others acknowledged, though, that social media behavior alone cannot provide complete assurance to the legitimacy or competence of a campaigner; instead, "it's just one flag on multiple indicators but I guess just showing there is regular updates going on there, there is content which is professional" (Participant 11).

Risk factors. Even with the assurances outlined above, most participants recognized some level of risk associated with crowdfunding, predominantly "the risk of them delivering a product which is completely not what you expected, or it being sort of not nearly as good quality as you wanted" (Participant 2). As such, risk awareness was more focused on competence to deliver the product, rather than legitimacy of the campaign. The extent to which participants were concerned about risk factors such as campaigner competence was mediated by the size of the investment being made. One participant notes that "if I'm only backing something for £50, I probably won't do all of that [due diligence], but if I'm going to put like £100, £200, £300, £500, I'll look into it a lot more" (Participant 11). The scale of investment that warrants this type of due diligence check will depend on the individual, but it is clear that this can impact decision making and attitudes toward project failure. As noted by another participant recalling a campaign that did not deliver at the end of the project, they "backed it at one of the inexpensive levels, so it didn't mean that much to me when it didn't come" (Participant 13).

4.2.6 Maintaining Trust Post Investment. The stages following funding a project can also be important, as this leaves an ongoing impression that will dictate how a funder portrays a campaigner to others in the future. While the importance of communication in the decision-making process has been emphasized above, personal experience indicated that after backing a project, participants were keen that communications be kept to a minimum. As long as there were no problems or delays, they "don't have a need to talk to them about it" (Participant 11), unless the end of the 
campaign is nearing when "there are some very urgent things and there is a lot of excitement behind it" (Participant 12).

Communication from the campaigner. In the cases where a project is delayed, participants note the sense of frustration witnessed in other campaign backers: "they're just full of rage" (Participant 13). Where these delays are well managed by the campaigner, most participants report that "as long as they [the campaigners] keep you updated with what's going on, then you don't panic as much" (Participant 6). While delays are often expected in the process given the nature of the platforms hosting new and inexperienced businesses, a severely extended waiting time means that the likelihood of project delivery can "become unrealistic, and especially if they lose contact" (Participant 3).

Desired assurances. In order to address some of the concerns that participants have about monetary loss in crowdfunding, they suggested potential solutions that might alleviate this, such as a "PayPal style grace period that ... by this date if they haven't delivered your product, then the money got bounced back to you" (Participant 11). Similarly, "a certain percentage of money protected, or even a protection guarantee if a company ran off with the money" (Participant 7) was an alternative suggestion. Additionally, participants called for explicit information around "the laws and regulations that protect you, if they were to be presented to you so you knew what protections you were getting, that would possibly go some way as to reassuring you when you invest" (Participant 6). Project vetting provided by the platform was another concept that participants felt would be reassuring, as well as campaigner references to provide additional verification. It was felt that assurances such as these would improve the decision-making process and enhance secure connectivity across crowdfunding platforms.

\subsection{Discussion}

Data gathered in this initial qualitative study aimed to address two research questions: first, to establish key factors underpinning investment decisions and establishment of trust in a campaigner, and second, to understand current due diligence processes that users engage in. In addressing the first research question, the findings from this study highlight factors associated with initial interest in the project and influences on investment decision making. A lot of the factors outlined support the investment decision-making model outlined by Liang et al. [2] and discussed in more detail earlier in this article.

Initial interest in the project was related mainly to personal interests and as such emphasizes commonalities between the potential funder and the campaigner. This is in line with the importance of value similarity, outlined by Liang et al. Value similarity is further reiterated in discussing the investment decision-making process though, with opinions of trusted friends and peers-many of whom will share our own values-deemed useful in this. In addition, project information quality, another factor outlined by Liang et al., can be seen in the current data. Participants placed emphasis on a campaign video as a good indicator of quality, suggesting that those campaigners who were not legitimate or unlikely to deliver on the product would also put less time and effort into generating the content for the campaign page. This is in line with previous research that has demonstrated that the mere presence of a campaign video can predict the number of investors a campaign will receive [14].

A drawback to the reliance on the campaign video to demonstrate a trustworthy campaign, as highlighted by some participants, was that this is an element where even if quality is high, this does not guarantee an ability to produce and effectively deliver the product being advertised. Although a well-made campaign video may go some way to alleviating risk factors, it does not necessarily demonstrate the competence of the campaigner. As such, the findings reported here seem to 
demonstrate an overwhelming reliance on social information to assess campaigner competence, through assessment of reputation and social credibility. Where strong evidence of fundraiser ability is available, through campaign history and previous business activity, this is valued by funders [16-18]. However, as many campaigners are bringing their first product to market, this information is often lacking and as such crowdfunding produces a unique paradigm where social information becomes a more valuable asset in investment decision making.

In the Literature Review, we suggest that the "fundraiser reputation" concept outlined in Liang et al.'s model could be reconsidered to incorporate wider social information instead of just reputation. This is supported within the data reported here to highlight the importance of broader "social credibility." Although there is some emphasis on the reputation of the campaigner in the decision-making process, through acknowledgment of reviews and comments from others, participants also reported reliance on connectedness and communication ability (as in [23]). By accessing information through social media, participants reported that they were able to gain an impression of how well a campaigner communicated with customers, particularly surrounding negative comments, and as such were able to make judgments about their engagement and commitment to the crowdfunding process.

The data from this study also consider how funders maintain trust following an investment, especially when there is a delay in the delivery of the product. In this scenario, communication from the campaigner was highlighted as a key assurance, in line with Kim et al.'s [5] model of trust maintenance during a delay. This model highlights a number of other factors-domain expertise, delay duration, background research, and funder identity-that influence the way in which a funder responds to a delayed project. Although the emphasis is on maintaining trust following investment rather than initial investment decision making, the model draws on similar information in understanding the trust relationship. With reference to prior experience and preinvestment due diligence checks, Kim et al.'s model suggests that funders are able to maintain trust if there is evidence to suggest a campaigner is trustworthy and reliable, in the same way this information can inform the initial decision to invest.

Many of the factors outlined within the data are also representative of Cialdini's [24] six principles of persuasion (reciprocation, liking, social proof, commitment, authority, and scarcity). In particular, a reliance on the opinions and perceptions of other crowdfunders and social media followers highlights the importance of social proof. While the effectiveness of good communication skills in supporting campaigners' social credibility can be seen as commitment to their campaign, the role of scarcity in terms of availability of the product was also highlighted by some participants, with the potential to encourage oversight of normal due diligence checks in order to ensure access to a limited-edition version. The presence of these persuasion techniques within campaigns not only reiterates the key factors surrounding decision making but also draws attention to a number of aspects that could be manipulated within a fraudulent campaign to elicit trust, and ultimately investment.

Most of the participants in this study acknowledged that there are risks associated with engaging in crowdfunding, particularly around a lack of legal regulation and security if a campaigner does not deliver a product. In answering our second research question, the data presented highlight a number of steps that participants reported taking in order to conduct due diligence checks before making an investment decision. Some of these tie in more broadly with the factors influencing decision making and can be incorporated within a broader model of decision making, such as assessment of project quality, prototype progression, prior crowdfunding experience, and social credibility of the fundraiser. However, one element that is somewhat overlooked in Liang et al.'s model is the role of social media in this process. While the content of a campaign page could be easily manipulated, participants perceived social media to be a more reliable source of information 
regarding the legitimacy of a campaigner. External platforms such as Facebook, Twitter, and Reddit provide additional information to verify the identity of a campaigner but also provide further social information from a wider audience of followers. These allow potential funders to essentially run "background checks" on a campaigner in order to provide assurance of the legitimacy of a campaign before investing. One issue with this, which will be discussed in more detail later in the article, is that the information presented on social media is also at risk of being manipulated [22] to elicit the desired response from a potential funder.

Across all aspects of the crowdfunding process, it becomes apparent that social factors play a key role in investment decision making, and funders are reliant on the opinions and behaviors of others to inform their own decisions. This data builds upon prior literature that looks at factors influencing campaign success, by engaging crowdfunders and exploring the processes that they consciously engage in when making investment decisions. As outlined earlier, the participant sample recruited for this study reached data saturation and included crowdfunders from a range of backgrounds with varying levels of experience. However, we acknowledge that the sample size may still be considered small and the generalizability to a wider population of potential funders cannot be guaranteed. In order to validate the findings reported in this study, a second quantitative study was conducted, providing a valuable mixed-methods approach to addressing the research questions posed [26]. This quantitative study places more emphasis on the due diligence process and use of external social information from social media, in line with our focus on the processes that users engage to address risk factors and navigate trust relationships in crowdfunding. In addition to this, the quantitative approach allows for additional individual difference factors to be considered in relation to the investment decision-making process, in order to assess whether specific psychological characteristics are associated with investment behavior.

\section{STUDY 2: SURVEY STUDY TO QUANTIFY FACTORS INFLUENCING CROWDFUNDING INVESTMENT DECISION MAKING}

Following on from Study 1, this study aims to triangulate the key findings around investment decision making-and in particular due diligence-with a broader participant sample while introducing additional measures of individual differences between participants. The study aims to address the same research questions as outlined in the Introduction, examining the investment decision-making process and the due diligence checks that participants engage in, both on the crowdfunding platform and via social media. Findings from Study 1 emphasized the importance of social information in the investment decision-making process, which will again be explored in this study. In order to explore the alleviation of risk and negotiation of trust in crowdfunding, this section of the article will place more emphasis on the due diligence checks that users engage in when making investment decisions. Due diligence, particularly outside of the crowdfunding platform, provides assurance to users with regard to campaign legitimacy and campaigner competence, as outlined in Study 1. This study will quantify the due diligence process while also exploring the relationship between perception of risk and likelihood to engage in due diligence checks. Expanding on the topics previously covered, this study will also take into account the potential role of individual difference factors including impulsivity, risk-taking behavior, and propensity to trust. In understanding the characteristics that might lead to increased investment likelihood and potential oversights in due diligence, this research may inform the development of security solutions that aim to protect the most at-risk users of crowdfunding platforms.

As outlined earlier on in this article, there is an inherent risk factor associated with crowdfunding investment. This is because campaigners often do not have a financial or business history to base investment decisions on and also due to the lack of legal regulations in place to protect a funder from fraudulent campaigns or from those that do not deliver the promised goods. This research 
will therefore assess individual differences in risk-taking behavior, to establish whether this acts as a precursor to investment, in particular focusing on financial and social risk taking to establish how these factors map on to crowdfunding behavior. Previous research into individual differences in risk-taking behavior has demonstrated links to gambling behavior [30] and increased likelihood to bid in a simulated online auction [31]. It is therefore hypothesized that individuals who are higher risk takers will typically make larger crowdfunding investments.

Individual differences in impulsivity have also previously been associated with financial risk taking [32] and gambling behavior [33]. As such, it is hypothesized that participants who display higher levels of impulsivity will make larger investments but may also be less inclined to engage in due diligence checks before making investment decisions. An additional factor that may impact the likelihood to engage in due diligence is propensity to trust-whereby a person has a general tendency to trust others, particularly in unfamiliar situations where the other person is a stranger [34]. As highlighted earlier in this article, trust is a crucial element of business transactions but is of particular relevance in crowdfunding where there are increased levels of uncertainty around the campaigner and the success likelihood of the proposed product. Propensity has been shown to be a strong predictor of trust [35] and as such may lead a potential crowdfunder to be more trusting of an unfamiliar campaigner, without feeling the need to engage in time-consuming due diligence checks. It is hypothesized that participants with a higher propensity to trust will be less likely to engage in due diligence checks.

While there is clear motivation to explore each of these individual difference factors in relation to crowdfunding-based on prior links with other financial risk-taking scenarios-this link has not previously been made within the academic literature. As such, this study will provide novel insight into the factors that impact typical crowdfunding behavior and investment habits.

In summary, this second study will use quantitative methods to validate findings from Study 1 around investment decision making and due diligence. It will also explore individual differences between users that may influence the processes associated with crowdfunding and the establishment of trust in an unknown campaigner.

\subsection{Materials and Methods}

Ethical approval for this research was granted by the University of Dundee School of Nursing and Health Sciences Research Ethics Committee. All participants gave fully informed written consent before taking part.

5.1.1 Participants. Two hundred and three active crowdfunders were recruited through an online participant site (prolific.ac). Although recruitment requirements specified that participants should have previously funded someone they did not know personally and engaged in either rewards- or equity-based crowdfunding, some participants did not meet these criteria. Therefore, these participants $(N=64)$ were removed from the analysis. This left a sample of 139 participants, consisting of 84 males, 52 females, and 3 who identified as transgender or "other." The mean age for the sample was 33.02 years $(\mathrm{SD}=9.53)$, with a range from 18 to 69 years.

5.1.2 Materials. A questionnaire was developed for the purpose of this study to triangulate findings from Study 1 with additional quantitative data. The core part of the questionnaire, reflecting on participant experiences with crowdfunding, was developed based on the themes drawn out of qualitative data in Study 1. As a result, this consisted of four sections:

(1) Demographics

(2) Crowdfunding experience

(3) Investment decision making

(4) Due diligence 
Questions around crowdfunding experience were designed to gather descriptive data about the participant sample, outlining type of crowdfunding, typical investment size, negative experiences, and confidence in making secure investments. To explore investment decision making, questions asked participants about how they discover campaigns and what their motivations are, before going on to explore the role of elements of the campaign page highlighted in Study 1 (e.g., professionalism, prototype progression) and social influence factors (e.g., familiarity, liking, reciprocity).

The section on due diligence focused initially on due diligence around the campaign page itself and then asked about checks that participants run on social media before deciding to invest in a campaign. For each of these sections, a sum score was taken based on a 5-point response scale to produce a due diligence $(N=3$; score range: $3-15)$ and a social media due diligence score $(N=8$; score range: 8-40) for each participant. Reliability analysis for the due diligence questions demonstrated that the item "the number of backers already supporting the campaign" reduced the Cronbach's alpha score, so this item was removed to produce an alpha score of .61 for the remaining three items. For social media due diligence, the eight items produced a Cronbach's alpha score of .80. The final part of this section asked participants about the extent to which they associate a series of risks with crowdfunding, such as "fake backers," "financial loss," and "loss of personal data." In order to generate a score for participants' risk awareness, a sum of responses to these six items was generated (maximum score: 30 ), producing a Cronbach's alpha score of .76. A list of the original scale questions given to participants can be seen in Appendix 1. Correlation matrices for all sets of questions that have been compiled into sum scores are shown in Appendix 2.

The final part of the questionnaire used well-established measures to assess individual differences in propensity to trust, impulsivity, and risk-taking behavior. In order to measure propensity to trust, the Propensity section from Mayer and Davis's [36] "Measures of Trust, Trustworthiness, and Performance Appraisal Perceptions" was used. Following reverse scoring as appropriate, responses to this scale generated a Cronbach's alpha score of .73 with all eight items included. Questions were measured on a 5-point scale, and a mean score across these was taken to give a propensity to trust score (score range: $1-5$ ). Impulsivity was measured using the 30-item Barratt Impulsiveness Scale (BIS-11 [37]), with responses given on a 4-point scale, and a sum score taken for each participant (score range: 30-120). The reliability for this scale generated a Cronbach's alpha score of .81. Finally, risk taking was measured using the 12 items from the financial and social subscales of the Domain Specific Risk-Taking Scale (DOSPERT [38]), with responses given on a 7-point scale. A sum score across these two subscales was calculated (score range: 12-84), as well as a score for each subscale individually (score range: 6-42). Reliability measures for these scores, assessed using Cronbach's alpha, were .78, .65, and .83, respectively. All of the scale response questions were presented to participants in matrices. In order to address issues of straightlining within the data, simple nondifferentiation analysis was conducted to detect participants who had given the same response for all questions within a scale. For each scale, data from participants who showed evidence of straightlining was removed. Table 2 indicates the proportion of participants who were straightlining for each scale and the sample size for that scale once these had been removed.

5.1.3 Procedure. Following sign-up on the online recruitment site (prolific.ac), participants were directed to the questionnaire, hosted on JISC Online Surveys. Participants were given full information about the purpose of the research and right to withdraw and, following consent, continued to complete the questionnaire. Following completion, participants were debriefed and thanked for their time.

\subsection{Results}

5.2.1 Crowdfunding Experience. Within our sample, 15.8\% reported that they had engaged in equity-based crowdfunding, $70.5 \%$ in rewards-based crowdfunding, and the remaining $13.7 \%$ in 
Table 2. Outline of Data Screening Relating to Straightlining

\begin{tabular}{lcc}
\hline Question Topic & \% Straightliners & $\begin{array}{c}\text { N Following Removal of } \\
\text { Straightliners }\end{array}$ \\
\hline Investment decision-making & 7.2 & 129 \\
Social influence & 2.2 & 136 \\
Due diligence & 10.1 & 125 \\
Social media & 7.9 & 127 \\
Risk factors & 7.9 & 128 \\
Propensity to trust & 0.7 & 137 \\
Impulsivity & 0.0 & 139 \\
Risk taking & 0.0 & 139 \\
\hline
\end{tabular}

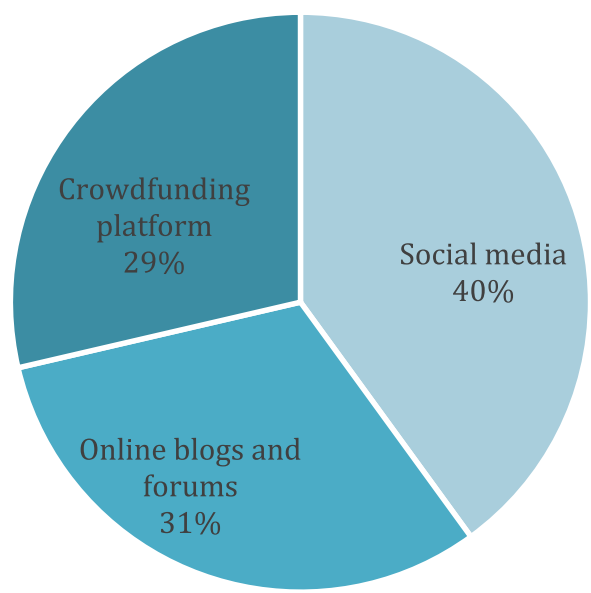

Fig. 1. Chart to demonstrate where participants typically source crowdfunding campaigns to support.

both. When asked about the average size of investment that they made in a crowdfunding campaign, the majority of participants $(N=54)$ invested $£ 21$ to $£ 50$, followed in frequency by smaller investments of $£ 1$ to $\$ 20(N=42)$, then $£ 51$ to $\$ 100(N=29)$ and over $\$ 100(N=14)$. The mean number of campaigns that participants had funded was 12.08 , with the majority of participants (50.4\%) classing themselves as beginner crowdfunders.

Of the crowdfunders recruited, 29.5\% $(N=41)$ reported that they had previously had a negative experience while supporting a crowdfunding campaign. The most common cause reported was a delay in receiving the advertised product $(N=30)$, followed by nondelivery of the product $(N=$ $21)$, poor communication from the campaigner $(N=18)$, loss of money $(N=12)$, and the final product not being as advertised $(N=3)$.

5.2.2 Investment Decision-Making Process. Participants were initially asked where they typically discover campaigns that they go on to invest in. Responses are shown in Figure 1, which highlights social media as the most common source.

Mean values for all questions relating to investment decision making can be seen in Appendix 1 . As shown in Figure 2, when asked about the importance of various elements within the crowdfunding campaign in the investment decision, participants rated both professionalism and prototype progression as more important than a personal approach and the campaign video $(p s<.001)$. A 


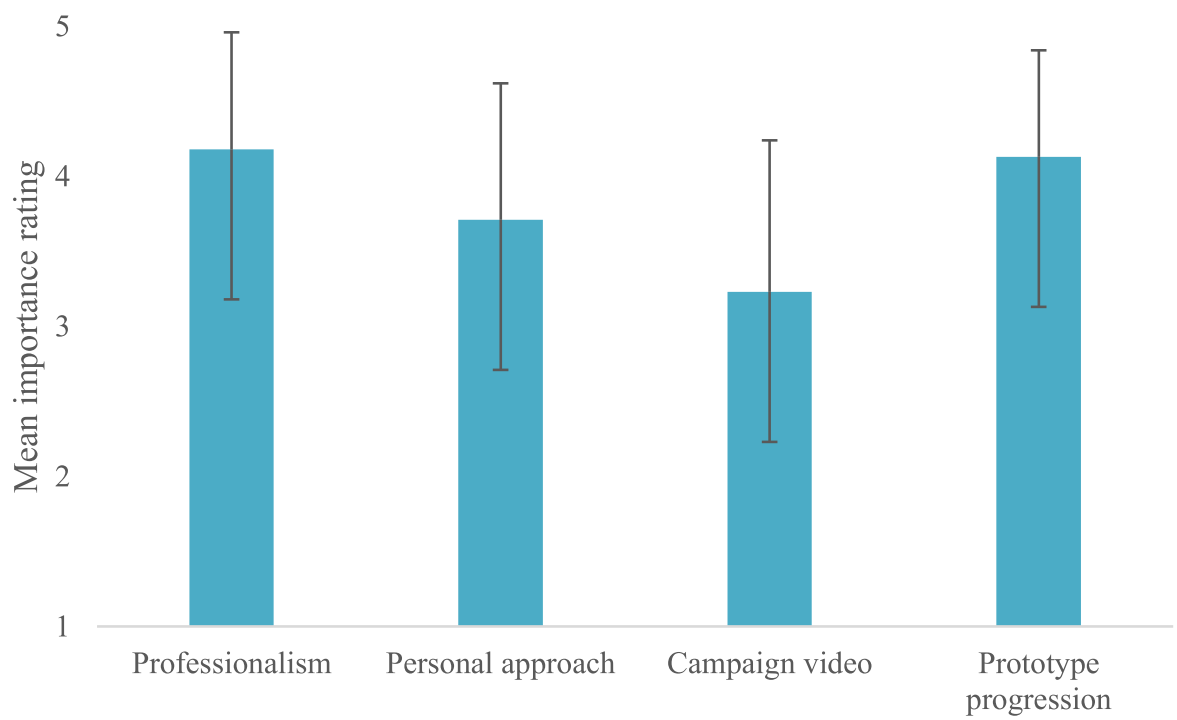

Fig. 2. Mean response to questions about importance of campaign elements to investment decision (standard deviation shown as error bars).

personal approach was also deemed more important than the campaign video $(\mathrm{p}<.001)$. No difference was found in the importance placed on professionalism and prototype progression $(p=.58)$. In relation to the social influence questions, participants demonstrated that they would be more likely to invest in a campaign when they had previous experience with the company, demonstrating the importance of familiarity. This was rated significantly higher than all other social influence factors explored, $p s<.01$.

5.2.3 Due Diligence. Based on questions relating to due diligence within the campaign page itself, a mean sum score of 12.66 ( $\mathrm{SD}=1.96$; max. score 15) was calculated. Again, individual item means can be seen in Appendix 1. Based on these, "How much communication the campaigner has had with other backers" was perceived less influential in investment decision making than "Comments from other backers and supporters of the project" and "The campaigner's prior history of crowdfunding projects" ( $p$ s < .05). However, all three items were rated as at least "a little" influential in the investment decision (all $M s>4$ ). Due diligence was compared across typical investment size categories, and no significant difference was found, $F(3,135)=0.24, p=.87$. This suggests that participants are no more or less likely to engage in due diligence checks, regardless of the amount of money they are typically risking in an investment.

Within our sample, $74.8 \%$ of participants reported that they have previously used social media to look into the background of a campaigner or company to inform their investment decision. Figure 3 shows the social media platforms most commonly used for such background checks.

A sum score for questions around social media due diligence generated a mean value of 33.14 $(\mathrm{SD}=4.46$; max. score 40$)$. Again, the mean values for all items here are above 3.5 , indicating acknowledgment from participants that all of these issues are at least "a little" influential on decision making. Social media due diligence scores were also compared across typical investment size groups, with no difference found, $F(3,123)=0.50, p=.69$. Those participants who reported that they use social media as a source for finding campaigns to fund placed higher importance on the social media due diligence measures $(M=34.24, \mathrm{SD}=3.35)$, based on their total score for these questions, than those who did not $(M=31.34, \mathrm{SD}=5.42), t(69.06$-adjusted for nonequal 


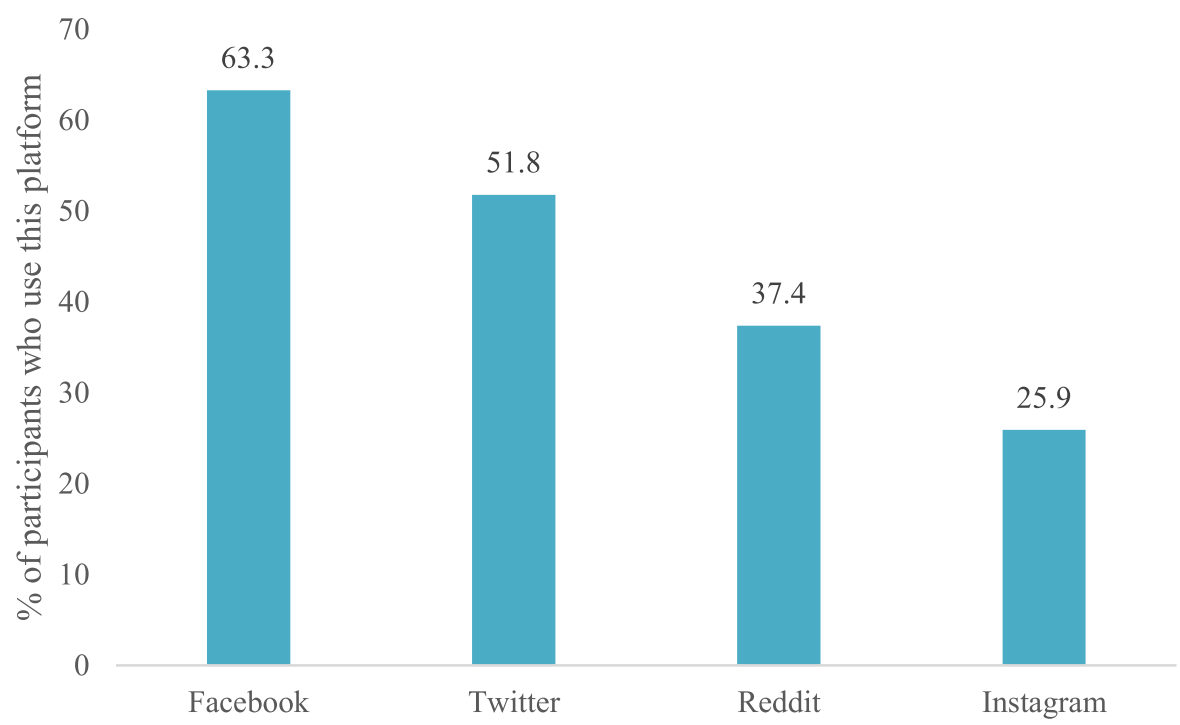

Fig. 3. Percentage of participants who report using each social media platform to perform background checks on a campaigner.

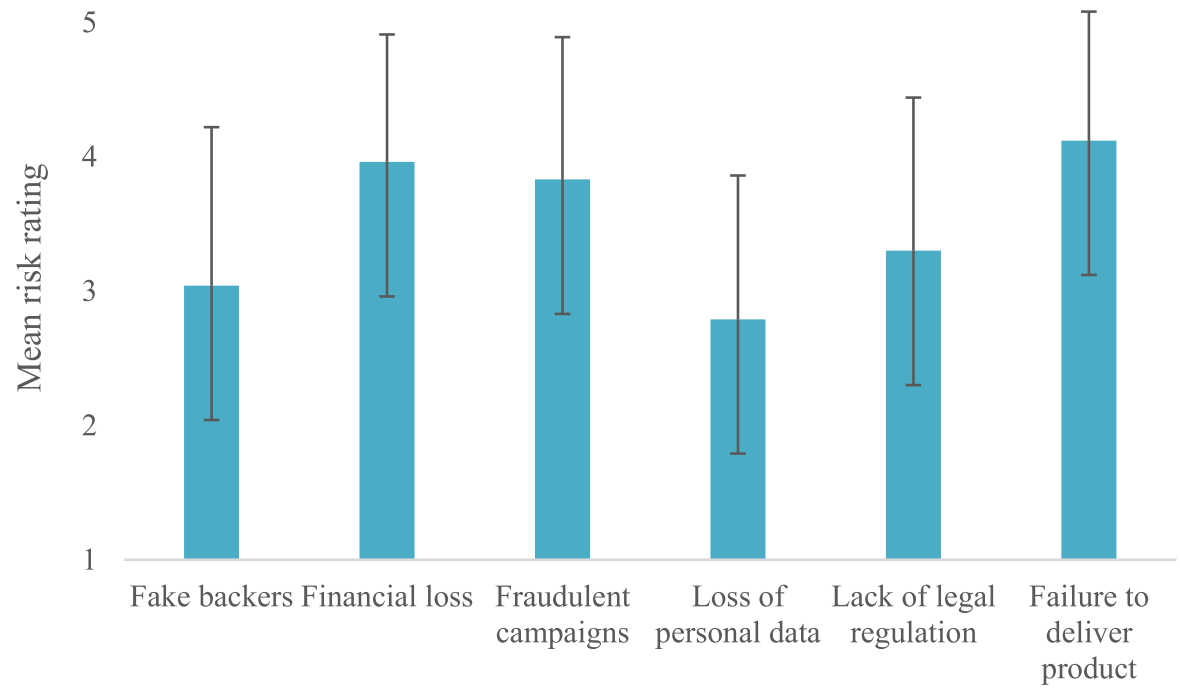

Fig. 4. Mean response to questions about risk factors associated with crowdfunding (SD shown as error bars).

variances $)=-3.35, p<.01$. This association between finding campaigns and due diligence may suggest that some users have a stronger link between crowdfunding and social media, and as such there may be a certain type of user who is more likely to rely on social media signals for conducting due diligence.

When asked whether they consider crowdfunding to be a risky activity, $61.9 \%$ reported that they did. Looking at specific risk factors (as shown in Figure 4), "failure to deliver the product" $(M=4.12$, $\mathrm{SD}=0.96)$ was considered significantly more of a risk than all other factors apart from "financial 
Table 3. Descriptive Statistics for Individual Difference Measures

\begin{tabular}{lcc}
\hline Measure & Mean & SD \\
\hline DOSPERT & 46.67 & 10.37 \\
Financial & 16.76 & 7.41 \\
Social & 29.91 & 5.43 \\
BIS11 & 62.43 & 9.79 \\
Propensity to trust & 22.23 & 4.39 \\
\hline
\end{tabular}

Table 4. Summary of Regression Analyses

\begin{tabular}{lllccc}
\hline $\begin{array}{l}\text { Regression } \\
\text { Analysis }\end{array}$ & Predictor & $£ 100+$ Investment Vs. & B & OR & $\boldsymbol{p}$ \\
\hline 1 & DOSPERT & $£ 1-£ 20$ & & & \\
& & $£ 21-£ 50$ & -0.08 & 0.92 & $<.01$ \\
& & $£ 51-£ 100$ & -0.08 & 0.93 & $<.05$ \\
\hline 2 & DOSPERT & $£ 1-£ 20$ & -0.06 & 0.94 & $<.05$ \\
& Financial & $£ 21-£ 50$ & -0.10 & 0.91 & $<.05$ \\
& $£ 51-£ 100$ & -0.07 & 0.94 & .10 \\
& DOSPERT & $£ 1-£ 20$ & -0.02 & 0.98 & .69 \\
& Social & $£ 21-£ 50$ & -0.07 & 0.94 & .33 \\
& & $£ 51-£ 100$ & -0.10 & 0.91 & .15 \\
& & -0.15 & 0.86 & $<.05$ \\
\hline
\end{tabular}

loss," ps $<.01$. On the other hand, "loss of personal data" $(M=2.79, \mathrm{SD}=1.07)$ was the lowestrated risk factor compared to all of the others, $p s<.05$. A sum score for risk perception across these factors was calculated, generating a mean score of $21.04(\mathrm{SD}=4.30$; max. score 30$)$. Simple linear regression demonstrated that recognition of risk factors predicted due diligence score $\left(\mathrm{R}^{2}=\right.$ .07 , Adjusted $\mathrm{R}^{2}=.06$ ), with increased recognition of risk factors linked to increased likelihood to engage with due diligence measures $(\beta=.26, t=2.86, p<.01), F(1,116)=8.16, p<.01$. No such relationship was found between risk perception and due diligence conducted on social media $(p=.37)$.

5.2.4 Individual Differences. Descriptive statistics for measures of risk taking, impulsivity, and propensity to trust are outlined in Table 3. Multinomial regression analysis demonstrated that scores on the DOSPERT scale were predictive of investment size, with those who invest $£ 100+$ on average having significantly higher risk-taking scores than the $£ 1$ to $£ 20(p<.01)$ and $£ 21$ to $£ 50(p<.05)$ categories, $\mathrm{X}^{2}(3, N=139)=8.26$, Nagelkerke $\mathrm{R}^{2}=.06, p<.05$. When the DOSPERT Financial and Social subscales were entered separately into a multinomial regression, a significant model was produced, $\mathrm{X}^{2}(6, N=139)=13.09$, Nagelkerke $\mathrm{R}^{2}=.10, p<.05$. Financial risk taking was significantly greater in those who typically invest $£ 100+$ compared to those who invest $£ 1$ to $£ 20$. Results for both analyses are summarized in Table 4 . No differences in investment size were found based on impulsivity and propensity to trust scores, ps $>.05$.

A series of regression analyses were conducted to explore the relationship between individual difference factors and likelihood to engage in due diligence checks, on the campaign page or through social media, when deciding whether to fund a campaign. No significant relationships were found, with all ps $>.05$. Further regression analysis demonstrated that propensity 
to trust was a significant predictor of awareness of crowdfunding-related risk factors $\left(\mathrm{R}^{2}=\right.$ .07 , Adjusted $\mathrm{R}^{2}=.06$ ). Increased propensity to trust predicted lower awareness of risk factors $(\beta=-.26, t=-2.95, p<.01), F(1,124)=8.69, p<.01$.

\subsection{Discussion}

In this study, a quantitative survey sought to triangulate findings from initial qualitative interviews with active crowdfunders. Questions explored various aspects of the crowdfunding process, with particular emphasis on due diligence checks, social media engagement, and individual differences between users. As in Study 1, prototype progression is highlighted as a key objective measure of competency to deliver the product, linked to the notion of project information quality, as highlighted by Liang et al. [2]. The role of social information is again emphasized in the decision-making process though, alongside objective reassurances. Initial perceptions of the campaigners and their competency to complete the project, with particular regard to professionalism, are deemed important. This emphasizes the human-centered nature of a peer economy such as that seen on crowdfunding platforms. Individual crowdfunding investors are making decisions not only about a product or organization that they want to support financially but also about the person who is behind the campaign.

As well as being a valuable source for finding out about campaigns in the first place, social media is again recognized by participants as a resource for conducting due diligence checks on a campaigner. Almost three-quarters of our participants (74.8\%) reported that they use social media when conducting such checks. Availability of social information is again recognized as valuable in allowing users to navigate the uncertainties of the crowdfunding process and support development of trust in a campaigner. Delving further into this due diligence process, it seems that information garnered from other crowdfunders is recognized as being one of the most important due diligence factors. This is consistent with findings from our interview data, with emphasis being placed on prior feedback available from other users. Social media provides additional assurances to the funder, through publicly available information demonstrating how others have rated the campaigners, as well as giving insight into how the campaigners interact with their customers or investors. This reliance on social proof and evidence that campaigners are committed to the project through updates and interaction with customers also reiterate the role of social psychological constructs around persuasion and the impact such information can have on decision making [24].

Although this persuasive content is consistent for all potential funders, not all will make the decision to invest. As such, it is of interest to consider the individual differences between users that may also influence the decision-making process. This study explored the role of risk-tasking tendencies, propensity to trust, and impulsivity. Impulsivity was not found to be a significant indicator of investment likelihood, possibly due to the more analytical approach that our participants reported taking, in conducting due diligence and background checks rather than making an on-thespot investment decision. A majority of our participants (61.9\%) did recognize that crowdfunding is a risky activity, and when looking in more depth at specific risk factors, it becomes clear that awareness of these factors increases the likelihood that a crowdfunder will engage in due diligence. Interestingly, when we measured participants' propensity to trust, we demonstrated that a higher propensity was associated with lower awareness of risk factors. This indicates that those who are predisposed to trust others do not necessarily consider the risks that may be associated with an investment activity such as crowdfunding. However, there is no direct evidence from our data to suggest that this propensity to trust has a role in the likelihood to engage in due diligence, or in fact a link to vulnerability.

Our data do suggest that a predisposition to engage in more risky activity, as measured by the DOSPERT scale, was predictive of investment size. Of particular interest is the finding that those 
participants who scored higher on the financial elements of the DOSPERT scale were significantly more likely to invest $£ 100$ or more on an individual crowdfunding campaign. This demonstrates that a willingness to take financial risks may lead to larger investments. Surprisingly, no direct link was found between a disposition for risk-taking behavior and the likelihood to engage in due diligence. This suggests that even though those users who demonstrate a higher disposition to risk taking are willing to invest more, they are still engaging in due diligence checks in an attempt to protect themselves before doing so.

Overall, findings from this study further support those reported in our first study and reiterate the crucial role that social information plays in crowdfunding investment decision making and navigating the risks associated with this. Information about the campaigner on a personal level and information garnered from the opinions of other customers and investors are consistently found to be influential factors. Further to this, data from this study demonstrate the role that individual differences in risk-taking behavior can play on the size of investments made. Understanding more about the individuals who engage in risky crowdfunding behaviors, as well as understanding the factors underpinning investment, provides a grounding for increased user protection when engaging with this process.

\section{GENERAL DISCUSSION}

The research reported in this article aimed to address two core research questions:

RQ1: Based on firsthand insights from crowdfunders, what factors underpin the investment decision-making process and development of trust in a campaigner?

RQ2: What due diligence processes do crowdfunders currently engage in, both on the campaign page and through external social media pages?

By employing a mixed-methods approach that sought firsthand insights from experienced crowdfunders, we were able to draw out the key influential factors that were present across both of these studies. In Study 1, qualitative interview data provided insight into the investment decisionmaking process, highlighting the importance of the campaigner's professionalism and the content of the campaign page (including video and a project plan) to the establishment of trust in a campaigner. In addition, the role of various social influence principles was apparent when participants discussed their typical decision-making process-in particular, familiarity, social proof, and liking [24]. Further to this, and in response to RQ2, participants outlined their typical due diligence process when considering a project to fund and highlighted campaigner history, prototype progression, and social media activity as key assurances that they would look for.

In Study 2, data from a quantitative survey reiterated many of these key findings, again emphasizing the role of prototype progression and liking the campaigner in the initial decision-making stages. Less importance was placed on the campaign video in this data compared to other factors, unlike in Study 1 and other previous research (e.g., [14]). However, it should be noted that the mean values for all factors outlined here were well above the midpoint, indicating some importance was placed on them. Study 2 placed a stronger emphasis on understanding the due diligence process, as well as considering individual differences between users. In contrast to Study 1, there was no quantitative evidence to support the notion that larger investments would lead to increased due diligence checks being performed. However, the role of information from other funders and via social media was again reiterated, with a majority of participants recognizing that crowdfunding is a risky activity, and as such due diligence is an important part of the process. Increased recognition of such risk was predictive of due diligence being carried out, suggesting that this acknowledgment may be a key part of protecting users against security threats such as fraudulent campaigns. 
However, it should be noted that the amount of variance in due diligence checking was only partially explained by recognition of risk factors $(\sim 7 \%)$, and as such this cannot be considered a sole contributing factor. Additional data would be needed to consider further factors that go into the decision to engage in due diligence checks. Finally, Study 2 also considered the role of individual difference factors between users that might predict investment behavior. Findings demonstrated that those who are more inclined to take risks are also likely to make larger crowdfunding investments, in line with previous research demonstrating links to gambling [30] and online auctions [31].

Earlier in the article, a theoretical model from Liang et al. [2] was outlined, which explains establishment of trust in crowdfunding scenarios. The authors highlight four key elements to building trust and as such increased investment likelihood: project information quality, fundraiser ability, fundraiser reputation, and value similarity. This model is further supported somewhat by the findings presented in this article, with evidence that participants are reliant on information about prototype progression (project information) and ability of the campaigner (through past campaigns and commitment to the project). The data collected in this research builds on the concept of fundraiser reputation though, to incorporate a wider array of social information that can be used to make judgments about the legitimacy of the campaigner. In fact, the key message that was persistent across both studies reported was the vital role that other people play in the decisionmaking process-emphasizing the social nature of engagement with crowdfunding. Unlike traditional investment methods, crowdfunding users are reliant on social information both about the campaigner and about the opinions of other users. In line with social psychological literature on influence and persuasion, a number of Cialdini's [24] principles of persuasion were present in the crowdfunding process. In Study 1, the role of scarcity was discussed, with a limited-edition version of a product being deemed more appealing, while across both studies, social proof through feedback from others and liking of the campaigner were found to play a crucial part in increasing the likelihood to invest in a campaign.

A second core finding from both studies that is not discussed in Liang et al.'s model was around the importance of social media in the due diligence process. Almost three-quarters of participants in Study 2 reported that they use social media to find background information on a campaigner, and this was also highlighted in Study 1. Again, social proof was a key element of this process, with social media being one method by which users could access information about how other users perceived the campaigner. Prior positive reviews and feedback were taken as a reinforcement of the campaigner's competency. Social media also provided reassurance though that the campaigner was genuine, with an emphasis placed on recent updates and activity on the page. This touches on another of Cialdini's principles-commitment-which suggests that consistency in behavior and actions is often perceived as trustworthy, and as such evidence of this in a campaigner could increase likelihood to invest. One key issue around the reliance on social media information for establishing trust and making judgments about campaign legitimacy, though, is the unreliability of signals produced. Social media information can easily be manipulated to emulate the social influence mechanisms shown to be persuasive to users in this research; for example, multiple fake accounts can be used to suggest strong communication ability, and fake reviews can be added to a page to suggest social proof. Although researchers have previously demonstrated that fraudulent campaigners are less likely to have a social media presence [18], it is plausible that in a minority of more sophisticated cases, a positive social media presence could be faked in order to increase believability of a fraudulent campaign. Social media presence alone has been shown to increase likelihood that a campaign will reach its target $[20,21]$, and as such users should be aware of the unreliability of signals available through social media, with support needed to help them effectively navigate this information and ensure that trust is being placed in the right campaigners. 
Based on our findings, which demonstrate the importance of social information and social media on the decision-making process, it is important to recognize this in future attempts to protect users from fraudulent crowdfunding campaigns. It has been noted by previous researchers that reputation systems, such as those used on other peer-based platforms including AirBnB and Uber, are not plausible in crowdfunding due to new campaigners not having this data available [5]. As well as the need to identify fraudulent campaigns, the need to verify this social information is also vital to support legitimate campaigners who do not have feedback available from previous customers. These campaigners may be disadvantaged in the crowdfunding sphere, as investors do not have the desired social information available to them to inform the decision-making process. This may in part explain the low success rate for crowdfunding campaigns in general, with less than $50 \%$ receiving their funding target. As outlined earlier, this research forms part of a wider project, which is developing block-chain-based security services that aim to verify social information from a variety of sources as a way of addressing the unreliability of these signals. This will support nonexperts to navigate the vast information available to them when conducting due diligence checks around crowdfunding campaigns. By incorporating information from personal accounts as well as any prior business activity, this approach does not disadvantage first-time campaigners. The solution is effectively generating a "social credit score" for campaigners, giving potential investors an indication of their legitimacy from the social perspective that they are so often reliant on in their decision-making anyway.

\subsection{Limitations and Future Research}

While the qualitative nature of the data gathered in Study 1 provides a rich dataset with key insights into investment decision making, we acknowledge that the sample size for this study is small $(N=11)$. However, care was taken to ensure that data saturation was reached within this sample, and wide recruitment meant that participants from a range of backgrounds and geographical locations could be sampled. Regardless, care should be taken in assuming generalizability of this data. Further validation of the data was established, though, through the triangulation of these findings with a larger quantitative dataset (Study 2), providing added assurance. Consistent findings across both studies reported provide a solid grounding for conclusions around the importance of social information in crowdfunding.

It is important to also acknowledge though that the data collected in Study 2 may be subject to typical biases associated with self-report data-in the sense that participants are being asked to reflect upon their own crowdfunding behavior and may not be able to put themselves in that situation while completing a survey. It is worth also noting that there is a gender imbalance in both studies, which may affect the findings, again reiterating the need for caution in assuming generalizability of the data.

Future research may benefit from the addition of behavioral measurements of decision-making to strengthen the findings reported here and move away from reliance on self-report methods. This research has elicited primary data from crowdfunding users, whereas a lot of previous research has relied on secondary analysis of campaign pages. However, asking participants to rate actual crowdfunding campaigns, with levels of available social information manipulated, would provide a more accurate and empirically robust representation of how this influences participant decisions. The data reported here provides a good grounding for ongoing research in this area and provides direction for researchers wishing to explore this topic in more depth. A further consideration in terms of improving the applicability of this research knowledge is to consider differences in crowdfunder motivation. Ryu and Kim [39] outline a taxonomy of funder types, each with different motivations and objectives for engagement in the crowdfunding process. It would be interesting to consider whether the factors that are prioritized when making investment decisions differ between these 
different types of funders. In developing this more in-depth understanding of individual users, the security solutions such as those outlined in this article may be tailored more appropriately to support and provide assurances to users.

\section{CONCLUSIONS}

Across two studies, we report findings that emphasize the key processes that crowdfunders undertake when deciding whether or not to invest in a campaign, incorporating initial decision making and due diligence checks that potential funders undertake. We build on previous research that has outlined elements of the decision-making process, providing firsthand accounts from experienced crowdfunders. By developing an understanding of the psychological mechanisms underpinning investment decisions, as we have started to in the research reported here, we can gather a more in-depth understanding of how users behave. This is a crucial element to the ongoing development of technological solutions that are designed to support users in navigating the due diligence process and ensuring that they can make informed decisions about who to place trust in when considering investment. Systems that are able to verify the social information that users report relying on to make decisions can alleviate the uncertainty associated with the crowdfunding process and provide added assurance when placing trust in an unknown party. Not only do our findings provide evidence of the social processes behind investment within the peer economy, they also start to draw on individual differences between users that might increase risky investment decisions. Ultimately, this allows us to build a picture of how crowdfunding users might be manipulated, as well as recognizing those users who may be more at risk to fraudulent campaigns or, in the case of investment size, have the most to lose.

\section{A APPENDICES}

\section{A1 Scale Response Survey Questions with Mean Rating across Participants}

\begin{tabular}{|c|c|c|}
\hline Topic & Questions & Mean/5 (SD) \\
\hline \multirow[t]{5}{*}{$\begin{array}{l}\text { Investment decision } \\
\text { making }\end{array}$} & $\begin{array}{l}\text { Please indicate how important you feel each of the following } \\
\text { elements of a crowdfunding campaign are to your investment } \\
\text { decision. }\end{array}$ & \\
\hline & 1. Professionalism of the campaign & $4.18(0.78)$ \\
\hline & $\begin{array}{l}\text { 2. A personal approach from the campaigner (e.g., story } \\
\text { about project background) }\end{array}$ & $3.71(0.91)$ \\
\hline & 3. Campaign video & $3.23(1.01)$ \\
\hline & 4. Progression of product prototype & $4.13(.71)$ \\
\hline \multirow[t]{7}{*}{ Social influence } & $\begin{array}{l}\text { I would be more likely to invest in a crowdfunding campaign } \\
\text { if... }\end{array}$ & \\
\hline & $\begin{array}{l}\text { 1. I had previous experience with the company running the } \\
\text { campaign (familiarity) }\end{array}$ & $3.91(0.92)$ \\
\hline & $\begin{array}{l}\text { 2. A campaign had raised } 85 \% \text { of the total funding goal, with } \\
8 \text { backers (low social proof) }\end{array}$ & $3.04(1.04)$ \\
\hline & $\begin{array}{l}\text { 3. I could purchase a limited-edition version of the product, } \\
\text { even if this is at a higher price (scarcity) }\end{array}$ & $3.09(1.13)$ \\
\hline & $\begin{array}{l}\text { 4. A campaign had raised } 20 \% \text { of the total funding goal, with } \\
96 \text { backers (high social proof) }\end{array}$ & $3.08(0.74)$ \\
\hline & $\begin{array}{l}\text { 5. I feel that I have a lot in common with the campaigner } \\
\text { (liking) }\end{array}$ & $3.67(0.90)$ \\
\hline & 6. I feel that I like the campaigner (liking) & $3.90(0.79)$ \\
\hline
\end{tabular}




\begin{tabular}{|c|c|c|}
\hline Topic & Questions & Mean/5 (SD) \\
\hline & $\begin{array}{l}\text { 7. A campaign had raised } 85 \% \text { of the total funding goal, with } \\
96 \text { backers (high social proof) }\end{array}$ & $3.63(0.92)$ \\
\hline & $\begin{array}{l}\text { 8. The campaigner had previously funded a crowdfunding } \\
\text { page of mine (reciprocation) }\end{array}$ & $3.01(1.07)$ \\
\hline & $\begin{array}{l}\text { 9. A campaign had raised } 20 \% \text { of the total funding goal, with } \\
8 \text { backers (low social proof) }\end{array}$ & $2.85(0.86)$ \\
\hline \multirow[t]{5}{*}{ Due diligence } & $\begin{array}{l}\text { To what extent do you consider the following factors when } \\
\text { making investment decisions? }\end{array}$ & \\
\hline & $\begin{array}{l}\text { 1. How much communication the campaigner had had with } \\
\text { other backers }\end{array}$ & $4.06(0.96)$ \\
\hline & $\begin{array}{l}\text { 2. Comments from other backers and supporters of the } \\
\text { project }\end{array}$ & $4.33(0.76)$ \\
\hline & 3. The campaigner's prior history of crowdfunding projects & $4.27(0.88)$ \\
\hline & $\begin{array}{l}\text { 4. The number of backers already supporting the campaign } \\
\text { (Item removed from analysis due to low reliability) }\end{array}$ & $4.00(0.96)$ \\
\hline \multirow[t]{9}{*}{ Social media } & $\begin{array}{l}\text { To what extent do you think each of the following factors, } \\
\text { relating to a company/campaigner's social media page, } \\
\text { influences your investment decision? }\end{array}$ & \\
\hline & 1. Having a social media presence & $3.97(1.05)$ \\
\hline & 2. Number of followers/likes & $3.50(1.03)$ \\
\hline & 3. Frequency of posting & $3.80(0.98)$ \\
\hline & 4. Quality of post content & $4.45(0.79)$ \\
\hline & 5. Relevance of content posted to campaign & $4.38(0.73)$ \\
\hline & 6. Level of interaction with followers & $4.16(0.80)$ \\
\hline & $\begin{array}{l}\text { 7. How recently the page has been updated (with news, } \\
\text { posts, information, etc.) }\end{array}$ & $4.41(0.77)$ \\
\hline & 8. Positive feedback from previous customers & $4.47(0.67)$ \\
\hline \multirow[t]{7}{*}{ Risk factors } & $\begin{array}{l}\text { To what extent do you associate the following security risks } \\
\text { with crowdfunding investment? }\end{array}$ & \\
\hline & 1. Fake backers & $3.04(1.18)$ \\
\hline & 2. Financial loss & $3.96(0.95)$ \\
\hline & 3. Fraudulent campaigns & $3.83(1.06)$ \\
\hline & 4. Loss of personal data & $2.79(1.07)$ \\
\hline & 5. Lack of legal regulation & $3.30(1.14)$ \\
\hline & 6. Failure to deliver product & $4.12(0.96)$ \\
\hline
\end{tabular}

\section{A2 Correlation Matrices}

Correlation Matrix for Questions Relating to Due Diligence

\begin{tabular}{lccc}
\hline Question & 1 & 2 & 3 \\
\hline 1 & 1.00 & & \\
2 & $.43^{*}$ & 1.00 & \\
3 & $.28^{*}$ & $.34^{*}$ & 1.00 \\
\hline Note: ${ }^{*} p<01$ & & &
\end{tabular}

Note: ${ }^{*} p<.01$. 
Correlation Matrix for Questions Relating to Due Diligence-Social Media

\begin{tabular}{lcccccccc}
\hline Question & 1 & 2 & 3 & 4 & 5 & 6 & 7 & 8 \\
\hline 1 & 1.00 & & & & & & & \\
2 & $.55^{* *}$ & 1.00 & & & & & & \\
3 & $.49^{* *}$ & $.67^{* *}$ & 1.00 & & & & & \\
4 & $.43^{* *}$ & $.40^{* *}$ & $.59^{* *}$ & 1.00 & & & & \\
5 & .14 & .16 & $.36^{* *}$ & $.48^{* *}$ & 1.00 & & & \\
6 & .15 & $.27^{* *}$ & $.33^{* *}$ & $.34^{* *}$ & $.35^{* *}$ & 1.00 & & \\
7 & $.21^{*}$ & $.20^{*}$ & $.35^{* *}$ & $.45^{* *}$ & $.46^{* *}$ & $.42^{* *}$ & 1.00 & \\
8 & .06 & $.18^{*}$ & $.18^{*}$ & $.26^{* *}$ & $.28^{* *}$ & $.33^{* *}$ & $.29^{* *}$ & 1.00 \\
\hline
\end{tabular}

Note: ${ }^{* *} p<.01,{ }^{*} p<.05$.

\section{Correlation Matrix for Questions Relating to Risk Factors}

\begin{tabular}{lcccccc}
\hline Item & 1 & 2 & 3 & 4 & 5 & 6 \\
\hline 1 & 1.00 & & & & & \\
2 & $.46^{* *}$ & 1.00 & & & & \\
3 & $.44^{* *}$ & $.45^{* *}$ & 1.00 & & & \\
4 & $.31^{* *}$ & $.20^{*}$ & $.30^{* *}$ & 1.00 & & \\
5 & $.18^{*}$ & $.18^{*}$ & $.29^{* *}$ & $.60^{* *}$ & 1.00 & \\
6 & $.29^{* *}$ & $.45^{* *}$ & $.49^{* *}$ & $.29^{* *}$ & $.33^{* *}$ & 1.00 \\
\hline Note: ${ }^{* *} p<.01,{ }^{*} p<.05$. & & & &
\end{tabular}

\section{REFERENCES}

[1] Y. Song and R. van Boeschoten. 2015. Success factors for crowdfunding founders and funders. In Proceedings of the 5th International Conference on Collaborative Innovation Networks (COINs'15).

[2] T. P. Liang, S. P. J. Wu, and C. C Huang. 2019. Why funders invest in crowdfunding projects: Role of trust from the dual-process perspective. Information \& Management 56, 1 (2019), 70-84.

[3] Y. Lei, A. Yayla, and S. Kahai. 2018. Unique challenges of decision-making process on crowdfunding platforms-an exploratory study. In Proceedings of the 51st Hawaii International Conference on System Sciences.

[4] D. M. Rousseau, S. B. Sitkin, R. S. Burt, and C. Camerer. 1998. Not so different after all: A cross-discipline view of trust. Academy of Management Review 23, 3 (1998), 393-404.

[5] Y. Kim, A. Shaw, H. Zhang, and E. Gerber. 2017. Understanding trust amid delays in crowdfunding. In Proceedings of the 2017 ACM Conference on Computer Supported Cooperative Work and Social Computing (1982-1996). ACM.

[6] E. M. Gerber and J. Hui. 2013. Crowdfunding: Motivations and deterrents for participation. ACM Transactions on Computer-Human Interaction (TOCHI) 20, 6 (2013), 34.

[7] A. Agrawal, C. Catalini, and A. Goldfarb. 2014. Some simple economics of crowdfunding. Innovation Policy and the Economy 14, 1 (2014), 63-97.

[8] R. T. Harrison and M. R. Dibben. 1997. The role of trust in the informal investment decision: An exploratory analysis. Entrepreneurship Theory Practice 20, 2 (1997), 63-81.

[9] M. Kang, Y. Gao, T. Wang, and H. Zheng. 2016. Understanding the determinants of funders' investment intentions on crowdfunding platforms: A trust-based perspective. Industrial Management and Data Systems 116, 8 (2016), 18001819.

[10] R. E. Petty and J. T. Cacioppo. 1986. The elaboration likelihood model of persuasion. Communication and Persuasion, 1-24. Springer, New York, NY.

[11] Federal Trade Commission. 2015. Crowdfunding project creator settles FTC charges of deception. Retrieved April 15, 2019, from https://www.ftc.gov/news-events/press-releases/2015/06/crowdfunding-project-creator-settlesftc-charges-deception.

[12] Federal Trade Commission. 2019. FTC charges operator of crowdfunding scheme. Retrieved August 16, 2019, from https://www.ftc.gov/news-events/press-releases/2019/05/ftc-charges-operator-crowdfunding-scheme. 
[13] Q. Zhao, C. D. Chen, J. L. Wang, and P. C. Chen. 2017. Determinants of backers' funding intention in crowdfunding: Social exchange theory and regulatory focus. Telematics and Informatics 34, 1 (2017), 370-384.

[14] S. Bi, Z. Liu, and K. Usman. 2017. The influence of online information on investing decisions of reward-based crowdfunding. Journal of Business Research 71 (2017), 10-18.

[15] D. J. Kim, D. L. Ferrin, and H. R. Rao. 2008. A trust-based consumer decision-making model in electronic commerce: The role of trust, perceived risk, and their antecedents. Decision Support Systems 44, 2 (2008), 544-564.

[16] M. G. Colombo, C. Franzoni, and C. Rossi-Lamastra. 2015. Internal social capital and the attraction of early contributions in crowdfunding. Entrepreneurship Theory and Practice 39, 1 (2015), 75-100.

[17] D. Zvilichovsky, Y. Inbar, and O. Barzilay. 2015. Playing both sides of the market: Success and reciprocity on crowdfunding platforms. SSRN Electronic fournal. Retrieved May 8, 2017, from https://papers.ssrn.com/sol3/papers.cfm? abstract_id=2304101.

[18] D. J. Cumming, L. Hornuf, M. Karami, and D. Schweizer. 2016. Disentangling Crowdfunding from Fraudfunding. Max Planck Institute for Innovation \& Competition Research Paper No. 16-09.

[19] A. Xu, X. Yang, H. Rao, W. T. Fu, S. W. Huang, and B. P. Bailey. 2014. Show me the money!: An analysis of project updates during crowdfunding campaigns. In Proceedings of the SIGCHI Conference on Human Factors in Computing Systems, 591-600. ACM.

[20] V. Skirnevskiy, D. Bendig, and M. Brettel. 2017. The influence of internal social capital on serial creators' success in crowdfunding. Entrepreneurship Theory and Practice 41, 2 (2017), 209-236.

[21] V. Rakesh, J. Choo, and C. K. Reddy. 2015. Project recommendation using heterogeneous traits in crowdfunding. In International AAAI Conference on Web and Social Media (ICWSM'15). 337-346.

[22] M. Wessel, F. Thies, and A. Benlian. 2016. The emergence and effects of fake social information: Evidence from crowdfunding. Decision Support Systems 90 (2016), 75-85.

[23] E. M. Gerber, J. S. Hui, and P. Y. Kuo. 2012. Crowdfunding: Why people are motivated to post and fund projects on crowdfunding platforms. In Proceedings of the International Workshop on Design, Influence, and Social Technologies: Techniques, Impacts and Ethics, 2, 11.

[24] R. B. Cialdini. 1993. Influence: The Psychology of Persuasion. New York: Quill William Morrow.

[25] A. Bandura and R. H. Walters. 1977. Social Learning Theory. Englewood Cliffs, NJ: Prentice-Hall.

[26] U. Kelle. 2006. Combining qualitative and quantitative methods in research practice: Purposes and advantages. Qualitative Research in Psychology 3, 4 (2006), 293-311.

[27] Y. Yang, D. Cooper, J. Collomosse, C. C. Dragan, M. Manulis, J. Steane, A. Manohar, J. Briggs, H. Jones, and W. Moncur. 2019. TAPESTRY: A blockchain based service for trust interaction online. Arxiv Preprint Arxiv:1905.06186.

[28] W. Neuman. 2014. Social Research Methods: Qualitative and Quantitative Approaches. Essex, UK: Pearson Education Limited.

[29] V. Braun and V. Clarke. 2008. Using thematic analysis in psychology. Qualitative Research in Psychology 3, 2 (2008), 77-101.

[30] S. Mishra, M. L. Lalumière, and R. J. Williams. 2017. Gambling, risk-taking, and antisocial behavior: A replication study supporting the generality of deviance. fournal of Gambling Studies 33, 1 (2017), 15-36.

[31] C. Deck, J. Lee, and J. Reyes. 2014. Investing versus gambling: Experimental evidence of multi-domain risk attitudes. Applied Economics Letters 21, 1 (2014), 19-23.

[32] J. Roger, E. Viding, and T. Chamarro-Premuzic. 2013. Instrumental and disinhibited financial risk taking: Personality and behavioral correlates. Personality and Individual Differences 55, 6 (2013), 645-649.

[33] M. W. J. Langewisch and G. R. Frisch. 1998. Gambling behavior and pathology in relation to impulsivity, sensation seeking, and risky behavior in male college students. Journal of Gambling Studies 14, 3 (1998), 245-262.

[34] J. B. Rotter. 1971. Generalized expectancies for interpersonal trust. American Psychologist 26, 5 (1971), 443.

[35] R. C. Mayer, J. H. Davis, and F. D. Schoorman. 1995. An integrative model of organizational trust. Academy of Management Review 20, 3 (1995), 709-734.

[36] R. C. Mayer and J. H. Davis. 1999. The effect of the performance appraisal system on trust for management: A field quasi-experiment. Journal of Applied Psychology 84, 1 (1999), 123.

[37] J. H. Patton, M. S. Stanford, and E. S Barratt. 1995. Factor structure of the Barratt impulsiveness scale. Fournal of Clinical Psychology 51, 6 (1995), 768-774.

[38] A. R. Blais and E. U. Weber. 2006. A domain-specific risk-taking (DOSPERT) scale for adult populations. SSRN Electronic fournal. Retrieved April 15, 2019, from https://papers.ssrn.com/sol3/papers.cfm?abstract_id=1301089.

[39] S. Ryu and Y. G. Kim. 2016. A typology of crowdfunding sponsors: Birds of a feather flock together? Electronic Commerce Research and Applications 16 (2016), 43-54.

Received April 2019; revised October 2019; accepted November 2019 